\title{
Analisis Saluran dan Efisiensi Pemasaran Sayuran Hidroponik di KUTP Hidrotani Sejahtera Desa Suka Maju Kecamatan Sunggal Kabupaten Deli Serdang \\ Hydroponic Vegetable Marketingand Eficiency Analysis at KUTP Hidrotani Sejahtera Suka Maju Village Sunggal District Deli Serdang Regency
}

\author{
Ahmad Sutan Nauli Lubis, Gustami Harahap, \& Mitra Musika Lubis \\ Program Studi Agribisnis Fakultas Pertanian Universitas Medan Area
}

Diterima: April 2021 Direview: April 2021 Disetujui: April 2021

*Corresponding author: E-mail: ahmadsutan@gmail.com

\begin{abstract}
Abstrak
Tujuan penelitian ini adalah untuk mengetahui saluran pemasaran sayuran hidroponik serta bagaimana tingkat efisiensi saluran pemasaran sayuran hidroponik di KUTP Hidrotani Sejahtera Desa Suka Maju Kecamatan Sunggal Kabupaten Deli Serdang. Metode penelitian yang digunakan adalah metode pengambilan sampel secara purposive (sengaja). Sampel pada penelitian ini adalah sebanyak 28 sampel. Berdasarkan data pra survey yang dilakukan terdapat dua pasar modern sebagai pedagang pengecer yaitu Brastagi Supermarket dan Transmart Carrefour yang menjual sayuran hidroponik. Konsumen yang diambil sebanyak 25 orang. Metode yang digunakan adalah snowball sampling serta metode perhitungan menggunakan Microsoft Excel. Data yang digunakan dalam penelitian ini adalah data primer dan data sekunder. Penelitian ini dilakukan pada bulan Mei 2019. Hasil penelitian menunjukkan bahwa saluran pemasaran sayuran hidroponik di KUTP Hidrotani Sejahtera Desa Suka Maju dimulai dari produsen kemudian ke pedagang pengecer hingga akhirnya ke konsumen. Saluran pemasaran sayuran hidroponik di tingkat lembaga pemasaran pedagang pengecer dengan tingkat efisiensi sebesar 0,15\%.
\end{abstract}

Kata Kunci: efisiensi; saluran pemasaran; sayuran hidroponik

\begin{abstract}
The purposes of this study are to determine the hydroponic vegetable marketing channels and efficiency level of hydroponic vegetables' marketing channels in KUTP Hidrotani Sejahtera Suka Maju Village, Sunggal District, Deli Serdang Regency. The research method used in this study was purposive sampling method. The sample of this research were 28 samples. Based on the survey conducted there were 2 modern markets as retailer, Brastagi Supermarket and Transmart Carrefour which sell hydroponic vegetables. Twenty-five customers were taken as samples. The method used was snowball sampling and Microsoft Excel calculation methods. Data used were primary and secondary data. The study was conducted in May 2019. The results showed that the marketing channel for hydroponic vegetable in KUTP Hidrotani Sejahtera began from producers to retailers then last to consumers. The hydroponic vegetable marketing channel at the level of the marketing agency was an efficient with efficient level of $0.15 \%$.
\end{abstract}

Keywords: efficiency; hydroponic vegetables; marketing channels

How to Cite: Lubis, A.S.N. Harahap, G. \& Lubis, M.M. (2021). Analisis Saluran dan Efisiensi Pemasaran Sayuran Hidroponik di KUTP Hidrotani Sejahtera Desa Suka Maju Kecamatan Sunggal Kabupaten Deli Serdang. Jurnal Agriuma. 3 (1): 9-19. 


\section{PENDAHULUAN}

Indonesia merupakan negara agraris yang mengutamakan hasil pertanian sebagai sumber penghasilan terbesarnya. Penurunan luas lahan pertanian di Indonesia akibat konversi dari sektor pertanian ke sektor non pertanian menyebabkan kegiatan budidaya pertanian mengalami kendala dalam penyediaan lahan. Tentu saja hal ini berdampak buruk bagi peningkatan kuantitas produksi pertanian, khususnya pangan untuk memenuhi kebutuhan masyarakat. Salah satu permasalahan yang mendasar dalam memajukan usaha pertanian di Sumatera Utara adalah masih lemahnya kemampuan sumber daya manusia dan kelembagaan usaha dalam hal penanganan pasca panen, pengolahan dan pemasaran hasil. Hal tersebut disebabkan karena pembinaan SDM pertanian selama ini lebih difokuskan kepada upaya peningkatan produksi (budidaya) pertanian, sedangkan produktivitas dan daya saing usaha agribisnis sangat ditentukan oleh kemampuan pelaku usaha yang bersangkutan dalam mengelola produk yang dihasilkan serta pemasarannya (Dinas Pertanian Provinsi Sumatera Utara, 2008).

Berdasarkan perkembangan pembangunan hortikultura pada komoditi sayuran menunjukan bahwa terjadi peningkatan kesadaran dan kepedulian masyarakat terhadap kesehatan. Sayuran dipilih sebagai alternatif dalam pola konsumsi masyarakat Indonesia. Sayuran merupakan sumber vitamin, mineral, dan serat yang diperlukan oleh tubuh. Oleh karena itu, semakin meningkatnya jumlah penduduk, pendidikan, dan kesejahteraan masyarakat akan berpengaruh terhadap permintaan sayuran (Direktorat Jenderal Hortikultura, 2013). Berdasarkan data yang diperoleh dari Badan Pusat Statistik (BPS) Provinsi Sumatera Utara. Produksi sayur-sayuran menurut jenis tanaman (Kw/Ha) dalam angka 2017 dapat dilihat pada tabel 1 sebagai berikut:

Tabel 1. Produksi Sayur-sayuran Menurut Jenis Tanaman (kw/ha) 2013-2017

\begin{tabular}{lllllll}
\hline No. & Jenis Tanaman & $\mathbf{2 0 1 3}$ & $\mathbf{2 0 1 4}$ & $\mathbf{2 0 1 5}$ & $\mathbf{2 0 1 6}$ & $\mathbf{2 0 1 7}$ \\
\hline 1. & Bawang Merah & 79,25 & 77,87 & 80,54 & 86,92 & 77,05 \\
2. & Bawang Putih & 72,4 & 54,29 & 51,68 & 41,18 & 39,79 \\
3. & Bawang Daun & 76,55 & 71,55 & 71,28 & 70,48 & 65,19 \\
4. & Kentang & 178,83 & 175,79 & 180,00 & 167,12 & 156,71 \\
5. & Kubis & 237,98 & 242,2 & 225,18 & 236,74 & 229,13 \\
6. & Petsai/Sawi & 117,7 & 114,35 & 119,04 & 120,42 & 116,31 \\
7. & Wortel & 190,37 & 198,16 & 202,22 & 200,10 & 196,45 \\
8. & Lobak & 131,13 & 129,84 & 124,43 & 94,49 & 128,55 \\
9. & Kacang Merah & 60,30 & 58,87 & 41,83 & 12,18 & 24,41 \\
10. & Kacang Panjang & 92,52 & 107,48 & 109,48 & 114,01 & 120,33 \\
11. & C a b e & 93,57 & 93,21 & 113,22 & 99,57 & 96,97 \\
12. & To m a t & 244,26 & 206,97 & 239,16 & 212,47 & 212,71 \\
13. & Terung & 164,69 & 161,92 & 175,54 & 213,46 & 224,34 \\
14. & Buncis & 130,76 & 156,9 & 138,25 & 115,84 & 135,27 \\
15. & Ketimun & 123,78 & 136,34 & 146,41 & 136,36 & 145,38 \\
16. & Labu Siam & 582,55 & 506,38 & 679,26 & 400,18 & 446,61 \\
17. & Kangkung & 81,92 & 82,56 & 102,15 & 63,38 & 64,18 \\
18. & B a y a m & 44,37 & 50,33 & 60,44 & 66,17 & 68,57 \\
19. & Kol Bunga & 139,84 & 145,94 & 114,1 & 149,73 & 142,02
\end{tabular}


Sumber: Dinas Tanaman Pangan dan Hortikultura Provinsi Sumatera Utara, 2015

Berdasarkan data pada Tabel 1, dapat dilihat rata-rata produksi sayur-sayuran menurut jenis tanaman di Provinsi Sumatera Utara dari tahun 2013 sampai pada tahun 2017 mengalami peningkatan produksi pada semua jenis tanama sayuran-sayuran, hal ini sejalan dengan tingginya kebutuhan masyarakat dalam mengonsumsi sayur-sayuran semakin hari semakin meningkat. Seiring dengan perkembangan ilmu pengetahuan dan kesadaran masyarakat tentang pentingnya kesehatan, sayuran-sayuran yang diproduksi tidak menggunakan pestisida mulai dipilih masyarakat untuk dikonsumsi sehari-hari.

Kondisi lahan pertanian yang semakin berkurang, sementara di sisi lain pemenuhan untuk kebutuhan pangan dari hasil produksi pertanian semakin meningkat. Berkaitan dengan hal ini, mendorong sektor pertanian dalam mengatasi kendala tersebut dengan meningkatkan penerapan sistem pertanian lahan sempit. Sistem pertanian lahan sempit yang saat ini sudah diterapkan adalah dengan menggunakan teknologi budidaya tanaman secara hidroponik.

Hidroponik merupakan sebutan untuk sebuah teknologi bercocok tanam tanpa menggunakan tanah. Media untuk menanam digantikan dengan media tanam lain seperti rockwool, arang sekam, zeolit, dan berbagai media yang ringan dan steril untuk digunakan. Hal yang terpenting pada teknik hidroponik adalah penggunaan air sebagai pengganti tanah untuk menghantarkan larutan hara ke dalam akar tanaman. Hidroponik sebenarnya berasal dari bahasa Yunani yaitu hydroponos. Kata hydroponos merupakan gabungan dari dua kata yaitu hydro yang atinya air dan ponos yang artinya bekerja. Jadi dapat dikatakan hidroponik merupakan proses pengerjaan dengan air, yaitu merupakan sistem penanaman dengan media tanam yang banyak mengandung air. Pemberdayaan air juga sebagai dasar pengembangan tubuh tanaman dan berperan dalam proses fisiologi tanaman (Prihmantoro, 2003).

Perusahaan Listrik Negara Pembangkitan Sumatera Utara (PT PLN Kitsu) yang memberikan program Corporate Social Responsibility (CSR) atau tanggung jawab sosial perusahaan kepada masyarakat, dengan program pemberdayaan masyarakat melalui kegiatan budidaya tanaman sayuran dengan menggunakan teknologi hidroponik yang dilaksanakan pada satu tempat usahatani yang bergerak di bidang produksi sayuran dengan sistem hidroponik yaitu Kelompok Usaha Tani dan Perikanan (KUTP) Hidrotani Sejahtera, Desa Suka Maju, Kecamatan Sunggal, Kabupaten Deli Serdang. Sayuran yang sudah berhasil diproduksi oleh kelompok usahatani KUTP Hidrotani Sejahtera nantinya akan dipasarkan langsung ke pasar-pasar modern atau supermarket besar di kota Medan dan telah menargetkan beberapa pasar modern atau supermarket yang akan dijadikan sebagai tempat penjualan terbesarnya.

Berdasarkan latar belakang yang telah diuraikan, maka peneliti tertarik untuk mengetahui saluran pemasaran sayuran hidroponik di Kelompok Usaha Tani dan Perikanan (KUTP) Hidrotani Sejahtera.

\section{Rumusan Masalah}

Berdasarkan latar belakang yang ada, maka rumusan masalah dalam penelitian ini adalah:

1. Bagaimana saluran pemasaran sayuran hidroponik di KUTP Hidrotani Sejahtera?

2. Bagaimana efisiensi pemasaran sayuran hidroponik di KUTP Hidrotani Sejahtera?

\section{Tujuan Penelitian}

Berdasarkan rumusan masalah, maka tujuan dari penelitian ini adalah:

1. Untuk mengetahui saluran pemasaran sayuran hidroponik di KUTP Hidrotani Sejahtera. 
2. Untuk mengetahui efisiensi pemasaran sayuran hidroponik di KUTP Hidrotani Sejahtera.

\section{Tinjauan Pustaka}

\section{Teknologi Hidroponik}

Hidroponik secara harfiah berarti, hydro yaitu air dan phonic yaitu pengerjaan. Sehingga secara umum berarti sistem budidaya pertanian tanpa menggunakan tanah tetapi menggunakan air yang berisi larutan nutrisi. Budidaya hidroponik biasanya dikerjakaan di dalam satu rumah kasa (greenhouse) untuk menjaga agar pertumbuhan tanaman secara optimal dan benar-benar terlindung dari pengaruh atau unsur luar seperti hujan, hama penyakit, iklim dan lain-lain. Keunggulan dari beberapa budidaya dengan menggunakan sistem hidroponik antara lain: (1) Kepadatan tanaman per satuan luas dapat dilipat gandakan sehingga menghemat penggunaan lahan. (2) Mutu produk seperti bentuk, ukuran, rasa, warna, kebersihan dapat dijamin karena kebutuhan nutrisi dapat dijamin karena kebutuhan nutrisi dalam tanaman dipasok secara terkendali di dalam rumah kasa. (3) Tidak tergantung musim/waktu tanam dan panen, sehingga dapat diatur sesuai dengan kebutuhan pasar (Rodiah, 2014).

\section{Saluran Pemasaran}

Saluran pemasaran merupakan alat atau sarana yang dapat digunakan oleh produsen untuk menyalurkan hasil produksinya hingga ke konsumen. Menurut (Kotlerdkk., 2002) saluran pemasaran dapat berlangsung apabila ada (a) adanya kelompok lembaga (b) adanya kegiatan atau fungsi yang dilaksanakan oleh lembaga tersebut (c) adanya arah pergerakan barang atau produsen serta kepemilikanya dari lingkungan produsen dan konsumen.

\section{Efisiensi Pemasaran}

Efisiensi pemasaran merupakan bentuk awal dari bekerjanya pasar persaingan sempurna, yang artinya sistem tersebut dapat memberikan kepuasan bagi lembaga-lembaga pemasaran yang terlibat. Efisiensi pemasaran merupakan sistem pemasaran yang efisien apabila memenuhi syarat mampu menyampaikan hasil dari petani produsen ke konsumen dengan biaya yang semurah-murahnya dan mampu mengadakan pembagian yang adil dari keseluruhan harga yang dibayar konsumen terakhir kepada pihak yang terlibat dalam kegiatan tersebut (Mubyarto, 1989).

\section{METODE PENELITIAN}

\section{Lokasi dan Waktu Penelitian}

Daerah penelitian ditentukan secara purposive (sengaja), artinya daerah penelitian dipilih berdasarkan tujuan penelitian. Tempat yang menjadi daerah penelitian yaitu Kelompok Usaha Tani dan Perikanan (KUTP) Hidrotani Sejahtera Desa Suka Maju, Kecamatan Sunggal, Kabupaten Deli Serdang. Berdasarkan data pra survey yang telah dilakukan terdapat 2 pasar modern yang menjual sayuran hidroponik terbesar, yaitu Brastagi Supermarket dan Transmart Carrefour. Dimana hasil penelitian di lokasi tersebut dapat bermanfaat untuk menentukan pemasaran yang tepat bagi usaha sayuran hidroponik. Penelitian ini dilakukan pada bulan Mei sampai dengan September 2019.

\section{Metode Pengambilan Sampel}

Metode menentukan lokasi penelitian dengan secara purposive (sengaja). Metode pengambilan sampel pada penelitian ini dengan menggunakan metode snowball sampling (bola 
salju) yaitu teknik pengambilan sampel yang mula-mula jumlahnya kecil, kemudian membesar (Sugiyono, 2013). Sampel yang digunakan pada penelitian ini adalah satu orang produsen sayuran hidroponik yaitu sebagai ketua di Kelompok Usaha Tani dan Perikanan (KUTP) Hidrotani Sejahtera, satu pedagang pengecer yaitu Brastagi Supermarket dan 25 orang konsumen yang membeli sayuran hidroponik untuk dijadikan sampel dalam penelitian ini. Sebagai tambahan untuk melengkapi hasil penelitian ini, diambil satu pasar modern yaitu Transmart Carrefour yang menjadi pedagang pengecer.

\section{Metode Pengumpulan Data}

Metode pengambilan data dilakukan dengan metode survei. Data yang dikumpulkan berupa data primer dan sekunder. Pengumpulan data primer dilakukan dengan metode wawancara dengan menggunakan daftar pertanyaan (kuesioner) terlampir.

Langkah-langkah yang dilakukan dalam pengumpulan data yaitu:

1. Kuesioner yaitu teknik pengumpulan data yang dilakukan dengan cara memberi seperangkat pertanyaan atau pernyataan tertulis kepada responden untuk dijawab.

2. Observasi yaitu pengamatan langsung kelokasi penelitian yaitu di Kelompok Usaha Tani dan Perikanan (KUTP) Hidrotani Sejahtera Desa Suka Maju, Kecamatan Sunggal, Kabupaten Deli Serdang.

3. Wawancara yaitu metode pengumpulan data dengan cara tanya jawab yang dikerjakan seccara sistematis dan berlandasan pada tujuan penelitian yang dijadikan sebagai sampel untuk melengkapi data dan informan yang dibutuhkan.

4. Studi pustaka yaitu catatan atau dokumentasi resmi tertulis dan dikeluarkan oleh badan pusat statistik dan lembaga lain yang ada kaitannya dengan penelitian ini.

\section{Metode Analisis Data}

Metode analisis data dengan metode deskriptif yaitu mengumpulkan, mengklasifikasikan, menganalisa dan menginterprestasikan data sehingga memberikan suatu gambaran yang lebih jelas tentang bagaimana saluran pemasaran sayuran hidroponik di lokasi penelitian. Pengolahan data yang akan dilakukan dengan mentabulasi data secara sederhana dalam bentuk yang lebih mudah dibaca dan diinterprestasikan.

Efisiensi pemasaran sayuran hidroponik dianalisis seacara kuantitatif dengan menggunakan margin pemasaran. Menurut Sudiyono (2001) margin pemasaran dapat diartikan sebagai analisis perbedaan harga tingkat produsen (harga beli) dengan harga di tingkat konsumen akhir (harga jual).

Secara matematis margin pemasaran dirumuskan sebagai berikut:

$$
\mathrm{Mi}=\mathrm{Psi}-\mathrm{Pbi}
$$

Dimana:

Mi: margin pemasaran pasar di tingkat ke-i

Psi: harga jual pasar di tingkat ke-i

Pbi: harga beli pasar di tingkat ke-i

Menurut Soekartawi (2002) adapun untuk menghitung efisiensi saluran pemasaran di daerah penelitian sbagai berikut: 


$$
\text { Efisiensi }=\frac{\text { Biaya Pemasaran }}{\text { Nilai Akhir Produk }} \times 100 \%
$$

Maka apabila saluran pemasaran lebih $<50 \%$ maka saluran pemasaran efisien, jika saluran pemasaran $>50 \%$ maka saluran pemasaran tidak efisien, dan jika saluran pemasaran $=$ $50 \%$ maka saluran pemasaran efisien.

\section{HASIL DAN PEMBAHASAN}

\section{Pola Saluran Pemasaran Sayuran Hidroponik}

Pola saluran pemasaran merupakan gambaran dari proses pemasaran yang dilakukan mulai dari produsen hingga sampai kepada konsumen dengan mekanisme tertentu. Pada penelitian ini saluran pemasaran sayuran hidroponik hanya memiliki satu saluran pemasaran, yang dimulai dari produsen sayuran hidroponik $\rightarrow$ pedagang pengecer sayuran hidroponik $\rightarrow$ konsumen sayuran hidroponik. Adapun pola pemasarannya sebagai berikut:

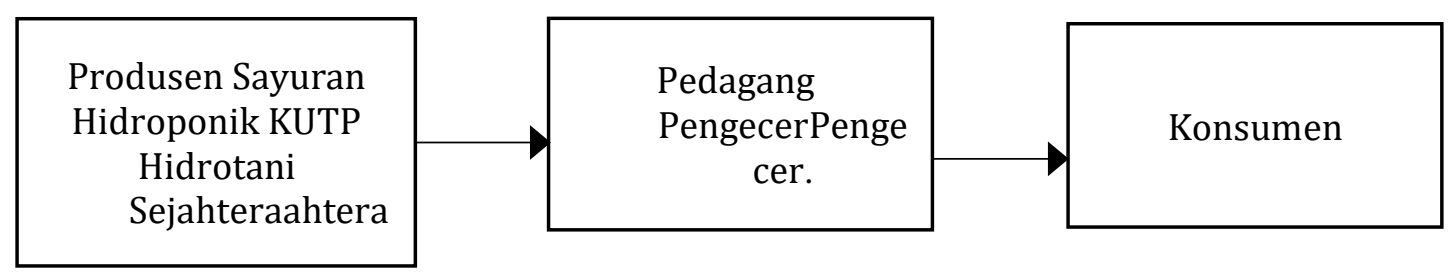

Gambar 1. Bagan Pola Saluran Pemasaran Sayuran Hidroponik di Kelompok Usaha Tani dan Perikanan (KUTP) Hidrotani Sejahtera.

Berdasarkan hasil penelitian yang dilakukan, produsen sayuran hidroponik Kelompok Usaha Tani dan Perikanan (KUTP) Hidrotani Sejahtera berada di Desa Suka Maju, Kecamatan Sunggal, Kabupaten Deli Serdang. Untuk pedagang pengecer dan konsumen didapatkan di Pasar Brastagi Supermarket dan Transmart Carrefour. Produsen sayuran hidroponik Kelompok Usaha Tani dan Perikanan (KUTP) Hidrotani Sejahtera menjual hasil produksi sayuran hidroponik dengan langsung mendatangi atau mengantar hasil produksinya ke pedagang pengecer yang sudah menjadi langganan tetapnya dengan harga Rp 35.000/Kg. Kemudian pedagang pengecer menjual kembali sayuran hidroponik tersebut ke konsumen dengan harga Rp 50.000-51.000/Kg. Adapun harga-harga yang ditetapkan oleh masing-masing lembaga pemasaran dapat dilihat pada Gambar 3 sebagai berikut:

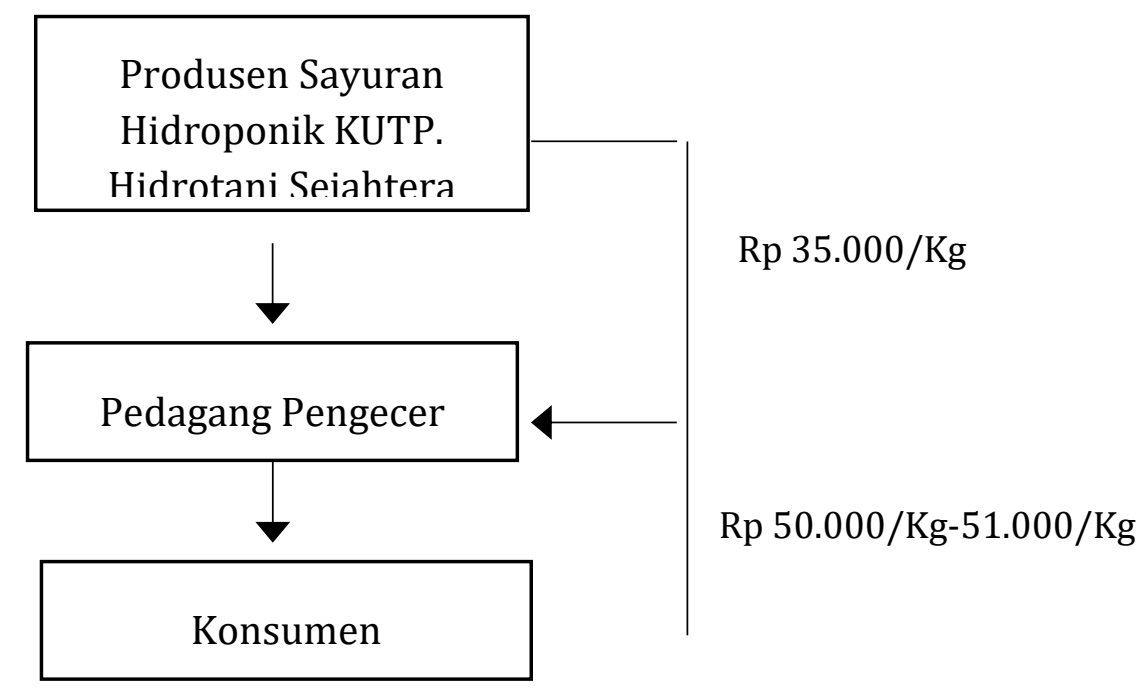


Gambar 2. Harga yang ditetapkan Oleh Masing-masing Lembaga Pemasaran Sayuran Hidroponik

Penyebab terjadinya perbedaan harga yang terjadi pada saluran pemasaran sayuran hidroponik yang ada disebabkan adaya biaya-biaya tambahan yang diperlukan oleh produsen dan pedagang pengecer seperti biaya produksi sayuran hidroponik, tenaga kerja, transportasi, pengemasan dan jumlah kuantitas yang diminta lembaga pemasaran sayuran hidroponik tersebut berbeda.

\section{Biaya Produksi dan Pemasaran Sayuran Hidroponik}

1. Biaya Produksi Sayuran Hidroponik

Biaya merupakan salah satu faktor yang dapat mempengaruhi keuntungan yang diperoleh pada suatu usaha. Biaya produksi yang dikeluarkan terdiri dari biaya benih, rockwoll, nutrisi, biaya listrik, dan biaya tenaga kerja. Dalam proses budidaya sayuran hidroponik tersebut, biaya produksi pada sayuran hidroponik sudah diperhitungkan oleh produsen, dapat dilihat pada tabel 8 berikut:

Tabel 2. Biaya Produksi Sayuran Hidroponik Kelompok Usaha Tani dan Perikanan (KUTP) Hidrotani Sejahtera Per Bulan

\begin{tabular}{ccccc}
\hline \multicolumn{1}{c}{ Produsen } & \multicolumn{3}{c}{ Biaya Produksi (Rp) } & Total Biaya \\
\cline { 1 - 3 } Keterangan & Pakcoy & Samhong & Sawi Putih & Produksi (Rp) \\
\hline Benih & 200.000 & 200.000 & 130.000 & 530.000 \\
Rockwoll & 937.000 & 937.000 & 535.000 & 2.409 .000 \\
Nutrisi & 750.000 & 225.000 & 225.000 & 1.200 .000 \\
Biaya listrik & 400.000 & 400.000 & 400.000 & 1.200 .000 \\
Tenaga Kerja & 6.000 .000 & 6.000 .000 & 6.000 .000 & 18.000 .000 \\
\hline Total & $\mathbf{8 . 2 8 7 . 0 0 0}$ & $\mathbf{7 . 7 6 2 . 0 0 0}$ & $\mathbf{7 . 2 9 0 . 0 0 0}$ & $\mathbf{2 3 . 3 3 9 . 0 0 0}$ \\
\hline Rata-rata & $\mathbf{1 . 6 5 7 . 4 0 0}$ & $\mathbf{1 . 5 5 2 . 4 0 0}$ & $\mathbf{1 . 4 5 8 . 0 0 0}$ & $\mathbf{4 . 6 6 7 . 8 0 0}$ \\
\hline
\end{tabular}

Sumber: Data Primer diolah, 2019

Berdasarkan Tabel 2 biaya penggunaan benih pada tiap sayuran berbeda tergantung pada harga benih dan jumlah produksi. hal ini dikarenakan biaya untuk satu bungkus benih cukup mahal. Biaya untuk penggunaan rockwoll dan nutrisi yang paling besar yaitu pada komoditas pakcoy dikarenakan produksinya paling banyak dalam sebulan. Nutrisi yang digunakan untuk semua sayuran hidroponik ini yaitu nutrisi AB mix.

Biaya listrik yang digunakan berasal dari hitungan pemakaian listrik di KUTP Hidrotani Sejahtera yaitu Rp 1.200.000 setiap bulannya. Pemakaian listrik sangat dibutuhkan untuk menggerakkan mesin pompa air sebagai sarana utama yang digunakan untuk mengalirkan larutan nutrisi ke semua tanaman sayuran hidroponik. Biaya tenaga kerja merupakan biaya yang dikeluarkan setiap bulannya untuk upah tenaga kerja di KUTP Hidrotani Sejahtera dengan jumlah pekerja sebanyak 12 orang tenaga kerja.

Dalam proses pemasaran sayuran hidroponik produsen mengemas terlebih dahulu sayuran hidroponik menggunakan plastik serta menempelkan stiker label di setiap kemasan, 
kemasan untuk setiap komoditas yang digunakan berukuran sama, sayuran hidroponik diantar langsung kepada pedagang pengecer untuk dipasarkan.

Adapun biaya pemasaran yang dikeluarkan oleh produsen dalam setiap bulannya dapat dilihat pada tabel 3 berikut:

Tabel 3. Biaya Pemasaran Sayuran Hidroponik Kelompok Usaha Tani dan Perikanan (KUTP) Hidrotani Sejahtera Per Bulan

\begin{tabular}{lcccc}
\hline \multirow{2}{*}{ Produsen } & \multicolumn{3}{c}{ Biaya Pemasaran (Rp) } & \multirow{2}{*}{ Total Biaya } \\
Keterangan & Pakcoy & Samhong & Sawi Putih & Pemasaran (Rp) \\
Plastik PE & 100.000 & 100.000 & 100.000 & 300.000 \\
Sticker Label & 60.000 & 60.000 & 60.000 & 180.000 \\
Transportasi & 500.000 & 500.000 & 500.000 & 1.500 .000 \\
\hline Total & $\mathbf{6 6 0 . 0 0 0}$ & $\mathbf{6 6 0 . 0 0 0}$ & $\mathbf{6 6 0 . 0 0 0}$ & $\mathbf{1 . 9 8 0 . 0 0 0}$ \\
\hline Rata-rata & $\mathbf{2 2 0 . 0 0 0}$ & $\mathbf{2 2 0 . 0 0 0}$ & $\mathbf{2 2 0 . 0 0 0}$ & $\mathbf{6 6 0 . 0 0 0}$ \\
\hline
\end{tabular}

Sumber Data Primer diolah, 2019

Dari Tabel 3, dapat dilihat total biaya pemasaran yang dikeluarkan oleh produsen sebesar Rp 1.980.000 dengan rata-rata sebesar Rp 660.000, biaya pemasaran yang dibutuhkan oleh produsen adalah plastik PE untuk kemasan sayuran hidroponik dan stiker label sebelum diantar kepada pedagang pengecer dengan menggunakan transportasi milik KUTP Hidrotani Sejahtera dengan total biaya yang dikeluarkan untuk pembelian bahan bakar sebesar $\mathrm{Rp}$ 1.500 .000 per bulannya.

1. Biaya Pemasaran Pedagang Pengecer

Pedagang pengecer berfungsi menyalurkan produk sayuran hidroponik yang dipasok oleh produsen agar sampai kepada konsumen. Untuk memenuhi hal tersebut pedagang pengecer memerlukan biaya pemasaran untuk menyalurkan produk sayuran hidroponik tersebut.

Brastagi supermarket dan Transmart Carrefour merupakan salah satu supermarket yang bergerak di bidang retail dengan spesifikasi sayuran dan buah segar. Salah satu produk sayuran yang ditawarkan Brastagi supermarket dan Transmart Carrefour adalah sayuran hidroponik. Adapun biaya pemasaran yang dibutuhkan oleh pedagang pengecer Brastagi Supermarket dan Transmart Carrefour dapat dilihat pada tabel 4 dan 5 berikut:

Tabel 4. Biaya Pemasaran Pedagang Pengecer Brastagi Supermarket

\begin{tabular}{|c|c|c|c|c|c|}
\hline \multirow{2}{*}{$\begin{array}{c}\text { Harga } \\
\text { Beli } \\
\text { (Rp/Kg) }\end{array}$} & $\begin{array}{c}\text { Harga } \\
\text { Jual } \\
\text { (Rp/Kg) }\end{array}$ & \multicolumn{2}{|c|}{ Biaya Pemasaran (Rp) } & $\begin{array}{c}\text { Total Biaya } \\
\text { Pemasaran } \\
\text { (Rp) }\end{array}$ \\
\hline 35.000 & 50.000 & 5.500 & 1.500 & 500 & 7.500 \\
\hline
\end{tabular}

Sumber: Data Primer diolah, 2019

Dapat dilihat pada Tabel 4, bahwa biaya pemasaran sayuran hidroponik yang dibutuhkan di Brastagi Supermarket adalah biaya plastik wrap, timbangan digital dan kertas label. Adapun total biaya pemasaran sebesar Rp 7.500/Kg. 
Tabel 5. Biaya Pemasaran Pedagang Pengecer Transmart Carrefour

\begin{tabular}{|c|c|c|c|c|c|}
\hline \multirow{2}{*}{$\begin{array}{c}\text { Harga } \\
\text { Beli } \\
\text { (Rp/Kg) }\end{array}$} & \multirow{2}{*}{$\begin{array}{c}\text { Harga } \\
\text { Jual } \\
\text { (Rp/Kg) }\end{array}$} & \multicolumn{3}{|c|}{ Biaya Pemasaran (Rp) } & \multirow{2}{*}{$\begin{array}{l}\text { Total Biaya } \\
\text { Pemasaran } \\
\text { (Rp) }\end{array}$} \\
\hline & & Plastik Wrap & Timbangan & Kertas Label & \\
\hline 35.000 & 51.000 & 5.500 & 1.500 & 1500 & 8.500 \\
\hline
\end{tabular}

Sumber: Data Primer diolah, 2019

Dapat dilihat pada Tabel 5 bahwa biaya pemasaran sayuran hidroponik yang dibutuhkan di Transmart Carrefour adalah biaya plastik wrap sebesar Rp 5.500 kemudian timbangan digital Rp 1.500 dan kertas label Rp 1.500. Adapun total biaya pemasaran yang dkeluarkan sebesar Rp $8.500 / \mathrm{Kg}$.

\section{Margin Pemasaran dan Efesiensi Pemasaran Sayuran Hidroponik}

Analisis margin merupakan analisis perbedaan harga di tingkat produsen dengan harga di tingkat konsumen. Menurut Sudiyono (2001) margin pemasaran secara matematis dihitung dengan rumus:

$$
\mathrm{Mi}=\mathrm{Psi}-\mathrm{Pb}
$$

Dimana:

Mi : margin pemasaran pasar di tingkat ke-i

Psi : harga jual pasar di tingkat ke-i

Pbi : harga beli pasar di tingkat ke-i

Menurut Soekartawi (2002) adapun untuk menghitung efisiensi saluran pemasaran di daerah penelitian sebagai berikut:

$$
\text { Efisiensi }=\frac{\text { biaya } \text { pemasaran }}{\text { nilai akhir } \text { produk }} \times 100 \%
$$

Maka apabila saluran pemasaran lebih $<50 \%$ maka saluran pemasaran efisiensi, jika saluran pemasaran $>50 \%$ maka saluran pemasaran tidak efisien, dan jika saluran pemasaran $=$ $50 \%$ maka saluran pemasaran efisien.

Margin pemasaran sayuran hidroponik merupakan pertambahan nilai atau harga jual dari produsen sayuran hidroponik Kelompok Usaha Tani dan Perikanan (KUTP) Hidrotani Sejahtera ke pedagang pengecer sampai dengan kepada konsumen akhir. Untuk mengetahui hal tersebut peneliti telah mengambil data dan mengolahnya dan hasilnya dapat dilihat pada tabel 6 berikut ini.

Tabel 6. Margin Pemasaran dan Efesiensi Pemasaran Sayuran Hidroponik di Brastagi Supermarket 
Ahmad Sutan Nauli Lubis, Gustami Harahap, \& Mitra Musika Lubis, Analisis Saluran dan Efisiensi Pemasaran Sayuran Hidroponik di KUTP Hidrotani Sejahtera Desa Suka Maju Kecamatan Sunggal Kabupaten Deli Serdang

\begin{tabular}{|c|c|c|c|c|c|}
\hline No & Uraian & Keterangan & $\begin{array}{c}\text { Harga Dan } \\
\text { Biaya (Rp/Kg) }\end{array}$ & Margin & $\begin{array}{c}\text { Efisiensi } \\
\text { Pemasaran } \\
\text { (\%) }\end{array}$ \\
\hline 1 & Produsen & Harga Jual & 35.000 & & \\
\hline \multirow[t]{3}{*}{2} & Pedagang & Harga Beli & 35.000 & & \\
\hline & Pengecer & $\begin{array}{c}\text { Harga Jual } \\
\text { Biava }\end{array}$ & 50.000 & 15.000 & 0.15 \\
\hline & & Pemasaran & 7.500 & & \\
\hline \multirow[t]{2}{*}{3} & Konsumen & $\begin{array}{c}\text { Keuntungan } \\
\text { Bersih }\end{array}$ & 7.500 & & \\
\hline & & Harga Beli & 50.000 & & \\
\hline
\end{tabular}

Tabel 7. Margin Pemasaran dan Efesiensi Pemasaran Sayuran Hidroponik di Transmart Carrefour

\begin{tabular}{|c|c|c|c|c|c|}
\hline No & Uraian & Keterangan & $\begin{array}{c}\text { Harga Dan } \\
\text { Biaya } \\
(\mathrm{Rp} / \mathrm{Kg}) \\
\end{array}$ & Margin & $\begin{array}{c}\text { Efisiensi } \\
\text { Pemasaran } \\
(\%)\end{array}$ \\
\hline 1 & Produsen & Harga Jual & 35.000 & & \\
\hline \multirow[t]{3}{*}{2} & Pedagang & Harga Beli & 35.000 & & \\
\hline & Pengecer & Harga Jual & 51.000 & & \\
\hline & & $\begin{array}{c}\text { Biaya } \\
\text { Pemasaran }\end{array}$ & 8.500 & 16.000 & 0,16 \\
\hline \multirow[t]{2}{*}{3} & Konsumen & $\begin{array}{l}\text { Keuntungan } \\
\text { Bersih }\end{array}$ & 7.500 & & \\
\hline & & Harga Beli & 51.000 & & \\
\hline
\end{tabular}

Efisiensi pemasaran sayuran hidroponik di pasar Brastagi Supermarket dan Transmart Carrefour dapat dilihat pada perhitungan sebagai berikut:

1. Brastagi Supermarket

$$
\begin{aligned}
\text { Efisiensi } & =\frac{\text { biaya pemasaran }}{\text { nilai akhir produk }} \times 100 \% \\
& =\frac{\text { Rp. } 7.500}{R p .50 .000} \times 100 \% \\
& =0,15 \%
\end{aligned}
$$

2. Transmart Carrefour

$$
\begin{aligned}
\text { Efisiensi } & =\frac{\text { biaya pemasaran }}{\text { nilai akhir produk }} \times 100 \% \\
& =\frac{R p .8 .500}{R p .51 .000} \times 100 \% \\
& =0,16 \%
\end{aligned}
$$

Berdasarkan tabel margin pemasaran dan perhitungan efisiensi pemasaran produsen sayuran hidroponik pada pedagang pengecer Brastagi Supermarket memiliki efisiensi sebesar 15\% dengan tingkat margin sebesar Rp15.000. Sedangkan untuk pedagang pengecer Transmart Carrefour memiliki efisiensi sebesar sebesar 16\% dengan tingkat margin sebesar Rp16.000. Kedua pasar modern tersebut memiliki saluran pemasaran yang efisien. Maka dapat dilihat bahwa saluran pemasaran yang paling efisien diantara kedua pedagang pengecer adalah Brastagi Supermarket dengan persentase sebesar 15\%. Dikarenakan biaya pemasaran yang diperlukan pedagang pengecer Brastagi Supermarket lebih kecil dibandingkan dengan biaya pemasaran di Transmart Carrefour.

\section{SIMPULAN}


Berdasarkan hasil penelitian dan analisis yang telah dilakukan mengenai analisis margin pemasaran dan efisiensi pemasaran sayuran hidroponik di Kelompok Usaha Tani dan Perikanan (KUTP) Hidrotani Sejahtera diambil kesimpulan bahwa saluran pemasaran sayuran hidroponik mulai dari produsen sayuran hidroponik Kelompok Usaha Tani dan Perikanan (KUTP) Hidrotani Sejahtera $\rightarrow$ pedagang pengecer $\rightarrow$ konsumen. Saluran pemasaran sayuran hidroponik pada pedagang pengecer Brastagi Supermarket memiliki saluran pemasaran yang lebih efisien dengan nilai efisiensi pemasaran sebesar $0,15 \%$.

\section{DAFTAR PUSTAKA}

Annisa, I. (2017). Analisis Pemasaran Bawang Merah di Kecamatan Cimenyan, Kabupaten Bandung, Provinsi Jawa Barat. Bogor: Skripsi. Departemen Agribisnis, Fakultas Ekonomi dan Manajemen, IPB.

Dinas Pertanian Provinsi Sumatera Utara. (2008). Produksi Pertanian. Medan: Distan.

Hartus, T. 2001. Berkebun Hidroponik Secara Murah. Jakarta: Penebar Swadaya.

Jannovar, E.A. (2016). Budidaya cara menanam bawang merah panduan lengkap. http://erotani.blogspot.co.id/2016/05/budidaya-cara-menanam-bawang- merah.html diakses pada 2016.

Karsono, S. (2002). Hidroponik Skala Rumah Tangga Memanfaatkan Rumah dan Pekarangan. Depok: PT. Agromedia Pustaka.

Kotler, P. (2005). Manajemen Pemasaran. Jilid 1 dan 2. Jakarta: PT Indeks Kelompok Gramedia.

Lingga, P. (2005). Hidroponik Bercocok Tanam Tanpa Tanah. Jakarta: Penebar Swadaya.

Mubyarto. (1989). Pengantar Ekonomi Pertanian. Jakarta: Edisi Ke-tiga, LP3S.

Nazaruddin. (1999). Budidaya dan Pengaturan Panen Sayuran Dataran Rendah. Edisi ke-4. Jakarta: Penebar Swadaya. 142 hal.

Philip, K. (2002). Manajemen Pemasaran Edisi Millenium. Jakarta: PT Prenhallindo.

Rodiah, I S. (2014). Pemanfaatan Lahan Dengan Menggunakan Sistem Hidroponik. Jurnal Universitas Tulungagung bonorowo $1(2)$.

Purnamasari, I A. (2010). Analisa Pemasaran Jeruk Di Kabupaten Bangli. Surakarta: Fakultas Pertanian. Universitas Sebelas Maret.

Rosdiana, BS. (2009). Analisis Pemasaran Sayuran Organik di PT. Agro Lestari Ciawi. Bogor: Skripsi Program Ekstensi Pertanian.

Rosliani, R. (2005). Budidaya Tanaman Sayuran dengan Teknik Hidroponik. Balai Penelitian Tanaman Sayuran Pusat Penelitian dan Pengembangan Hortikultura Badan Penelitian dan Pengembangan Pertanian.

Rukmana, R. (1995). Hama Tanaman dan Teknik Pengendalian. Jakarta: Bumi Aksara.

Rukmana, R. (1994). Bayam, Bertanam \& Pengelolahan Pascapanen. Yogjakarta: Kanisius.

Saaty, T L. (1988). Decision Making for Leaders, University of Pittsburgh.

Sepriani, S. (2015). Analisis Strategi Pemasaran Bunga Potong. Medan: Skripsi. Departemen Sosial Ekonomi Pertanian, Fakultas Pertanian, Universitas Sumatera Utara.

Simatupang, B. (2002). Analisis Strategi Pemasaran Sayuran Hidroponik Merek Delfarm Vegetables pada PT. Misadana. Bogor: Skripsi. Departemen Ilmu-ilmu Sosial Ekonomi Prtanian, Fakultas Pertanian, Institut Pertanian Bogor.

Soekartawi. (2002). Prinsip Dasar Manajemen Pemasaran Hasil - Hasil Pertanian Teori dan Aplikasinya. Jakarta: Raja Grafindo Persada.

Sudarsono. (1998). Ekonomi Sumber Daya Manusia. Jakarta: Universitas Terbuka.

Sudiyono, A. (2001). Pemasaran Pertanian. Malang: Universitas Muhammadiyah Malang.

Sugiyono. (2013). Metode Penelitian Pendidikan Pendekatan Kuantitatif, Kualitatif, dan R\&D. Bandung: Alfabeta.

Susila, A. D. (2013). Sistem Hidroponik. Departemen Agonomi dan Hortikultura. Bogor: Fakultas Pertanian. IPB.

Sutiyoso, Y. (2004). Hidroponik ala Yos. Jakarta: Penebar Swadaya.

Swastha, B. (1999). Saluran Pemasaran (Edisi ke 1). Yogyakarta: BPFE

Tim Karya Tani Mandiri. (2010). Pedoman Bertanam Jagung. Bandung: Nuansa Aulia. 